\title{
Characterization of Carbon Derived from Water Hyacinth as a Renewable Energy Sources
}

\author{
Rani Kusumaningtyas ${ }^{1}$, Wenny Maulina ${ }^{1, a}$, Supriyadi ${ }^{1}$ \\ ${ }^{1}$ Department of Physics, Faculty of Mathematics and Natural Sciences, University of Jember, \\ Jember, Jalan Kalimantan No 37 Jember 68121, Indonesia \\ awenny@unej.ac.id
}

\begin{abstract}
An alternative renewable energy sources, such as biomass, can be produced using the combustion process inside the furnace. In this work, carbon derived from water hyacinth be produced through carbonization process. The carbonization of water hyacinth was carried out at different temperature i.e. $400^{\circ} \mathrm{C}, 500^{\circ} \mathrm{C}$ and $600^{\circ} \mathrm{C}$ and subsequently analyzed with the SEM-EDX to determine the microstructure and atomic percentage of present elements. While the FTIR analysis was conducted to qualitatively verify the surface functional groups of carbon. The results of SEM-EDX analysis showed that the pores began to form at a carbonization temperature of $600^{\circ} \mathrm{C}$ and carbon content increased with increased temperature of carbonization process. FTIR analysis results showed that the functional groups in the carbon derived from water hyacinth had an absorption pattern with $\mathrm{OH}, \mathrm{C}-\mathrm{H}, \mathrm{C}-\mathrm{O}$, and $\mathrm{C}=\mathrm{C}$ bonds.
\end{abstract}

Keywords: Renewable Energy Sources, Water Hyacinth, SEM-EDX, FTIR

\section{Introduction}

Improvement of economic activity causes an increase in world energy demand. The use of renewable energy is increasingly needed to substitute energy from fossil fuels. The projected global energy demand in 2040 will be supplied by $74 \%$ from fossil fuels and $26 \%$ from renewable materials, while the contribution of bioenergy from agricultural waste biomass will be $10.4 \%$ [1]. The advantage of using energy from biomass sources are produces environmentally friendly $\mathrm{CO} 2$ emissions (zero carbon footprint) and can be regenerated by plants again, so it doesn't cause increase emission of greenhouse gases [2]. Thus, renewable biomass plays a significant role in the energy supply in the world, especially in Indonesia.

Indonesia is a country that has abundant biodiversity so that it can potentially be exploited. One of the most common biodiversity found in water areas is water hyacinth (Eichhornia crassipes). Water hyacinth is considered a highly invasive aquatic weed, infecting dam, lakes and irrigation channels. One major problem associated with water hyacinth is its rapid growth rate. It can easily adapt and compete with other aquatic plants causing a major threat to the aquatic environment. When not managed and controlled, these plants will cause blockage in bodies of water. Although water hyacinth is seen as a weed and is responsible for many environmental and health problems, much research has been done in order to find useful applications for these plant [3]. One of the application which is can be used as a biomass sources.

The renewable biomass generally includes three main components: cellulose, hemicellulose, and lignin; and cellulose and hemicellulose make up approximately $70 \%$ of the entire biomass [4]. Water hyacinth can potentially be a resource due its high carbohydrate content (18\% cellulose, $50 \%$ hemicellulose) [5]. Charcoal is a type of black carbon produced from carbonization process when biomass is heated in a closed container with little or no available air $[6,7]$. The carbonization is a process in which non-carbon compounds are removed so that 
organic cellulose can be decomposed into carbon. Determination of the exact carbonization temperature determines the quality of the charcoal. Here, different temperature in carbonization process are evaluated to clarify carbon derived from water hyacinth according to spectroscopy and microstructure analysis.

\section{Material and Methods}

The water hyacinth used in charcoal production was collected from one of the rivers in the Province of Lumajang in East Java. The water hyacinth is taken part of the stem was washed to removed adhering dirt and then dried under the sun. Once the sample dry, biomass cut into small pieces and was entered in the furnace, then the temperature of heating was set. The carbonization temperature is adjusted (according to variations at $400^{\circ} \mathrm{C}, 500^{\circ} \mathrm{C}$, and $600^{\circ} \mathrm{C}$ ) with a heating time of 1 hours each. After this carbonization process, sample crush until smooth at size of 200 mesh.

Based on the treatment of temperature at carbonization process, the following samples were obtained in this study:

Sample A1: water hyacinth charcoal at a carbonization temperature of $400^{\circ} \mathrm{C}$

Sample A2: water hyacinth charcoal at a carbonization temperature of $500^{\circ} \mathrm{C}$

Sample A3: water hyacinth charcoal at a carbonization temperature of $600^{\circ} \mathrm{C}$

Furthermore, sample was characterized using scanning electron microscopy-energy dispersive $x$-ray (SEM-EDX) and Fourier Transform Infrared (FTIR). SEM-EDX to determine the microstructure and atomic percentage of present elements in the sample. While the FTIR analysis was conducted to qualitatively verify the surface functional groups of carbon.

\section{Results and Discussion}

\section{Characterization of SEM-EDX}

SEM was used to identify the surface morphology of carbon derived from water hyacinth. The surface morphology of carbon derived from water hyacinth with variations in carbonization temperature of $400^{\circ} \mathrm{C}, 500^{\circ} \mathrm{C}$, and $600^{\circ} \mathrm{C}$, can be seen in Figure 1. Sample $\mathrm{A} 1$ and $\mathrm{A} 2$ with carbonization temperature are $400^{\circ} \mathrm{C}$ and $500^{\circ} \mathrm{C}$, respectively, shown nonporous structure of carbon. While sample A3 at carbonization temperature $600^{\circ} \mathrm{C}$ shown porous structure of carbon with diameter of pore in the amount of $0.572 \mu \mathrm{m}$. Carbonization causes the components of the material to degrade to produce gases $\left(\mathrm{CO}, \mathrm{CO}_{2}\right.$, hydrogen and methane), liquid products (tar, hydrocarbons, water) and solid products, namely charcoal. The formation of pores at high temperatures were due to the evaporation of volatile matter from the materials at the carbonization process. The carbonization process causes the breakdown of carbon chains and will be more optimal with an increase in temperature [8].

In this study, characterization of EDX aims to determine the atomic percentage of present elements in carbon derived from water hyacinth. Table 1 shown the elements content of carbon derived from water hyacinth with various temperature. The EDX results shown the percentage of carbon elements present in all the sample is above $80 \%$. The percentage of carbon elements in sample $\mathrm{A} 1, \mathrm{~A} 2$, and $\mathrm{A} 3$ were $82.70 \%, 87.76 \%$, and $89.37 \%$, respectively. It can be seen that the higher of the carbonization temperature causes the greater of the carbon content. This result accordance with the carbonization process which is explain that at temperatures of $310^{\circ} \mathrm{C}$ $510^{\circ} \mathrm{C}$ there is an increase in the amount of $\mathrm{CO}, \mathrm{CH}_{4}$, and $\mathrm{H}_{2}$ and tar whereas a decrease in the 
amount of pyrolignic acid and $\mathrm{CO}_{2}$. Meanwhile at a carbonization temperature of $500^{\circ} \mathrm{C}$ $1000^{\circ} \mathrm{C}$ there is an increase in carbon content [9].

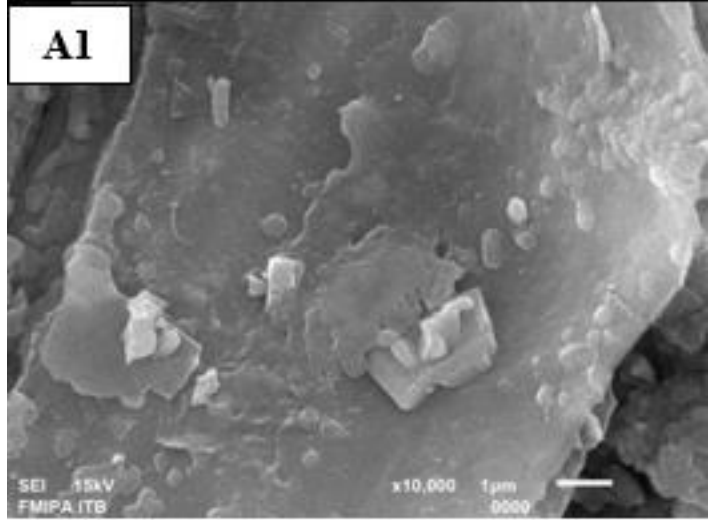

(a)

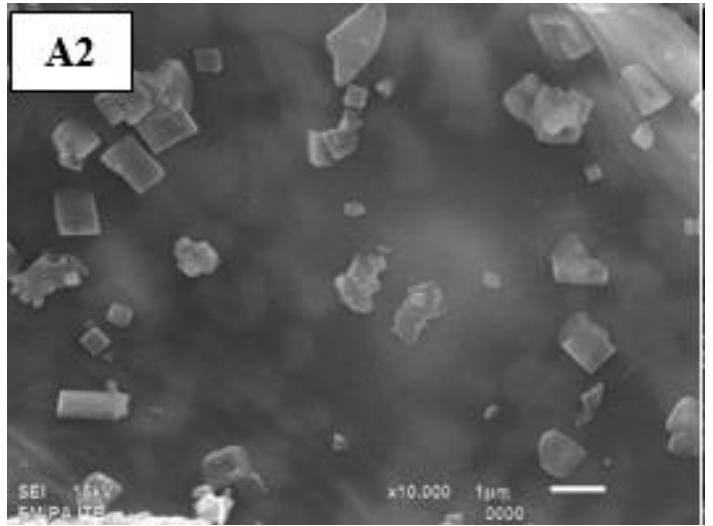

(b)

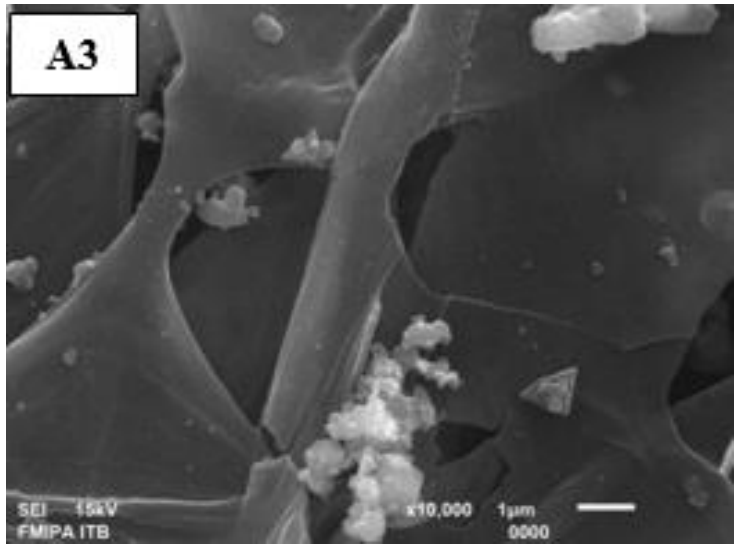

(c)

Figure 1. The surface morphology of carbon derived from water hyacinth at carbonization temperature (a) $400^{\circ} \mathrm{C}$ (sample A1), (b) $500^{\circ} \mathrm{C}$ (sample A2), and (c) $600^{\circ} \mathrm{C}$ (sample A3), respectively

Table 1. The elements content of carbon derived from water hyacinth at various temperature

\begin{tabular}{cccc}
\hline \multirow{2}{*}{ Element } & \multicolumn{3}{c}{ wt\% } \\
\cline { 2 - 4 } C & $\mathrm{A} 1$ & $\mathrm{~A} 2$ & $\mathrm{~A} 3$ \\
\hline $\mathrm{C}$ & 82.70 & 87.76 & 89.37 \\
$\mathrm{O}$ & 14.47 & 7.10 & 7.58 \\
$\mathrm{Na}$ & - & - & - \\
$\mathrm{Mg}$ & 0.41 & 0.31 & 0.81 \\
$\mathrm{Al}$ & 0.16 & - & - \\
$\mathrm{Si}$ & 0.37 & - & - \\
$\mathrm{S}$ & 0.14 & - & - \\
$\mathrm{Cl}$ & 0.47 & 2.25 & 0.99 \\
$\mathrm{~K}$ & 0.48 & 2.09 & 0.97 \\
$\mathrm{Ca}$ & 0.50 & 0.50 & 0.28 \\
$\mathrm{Zr}$ & 0.29 & - & - \\
\hline
\end{tabular}


Characterization of FTIR

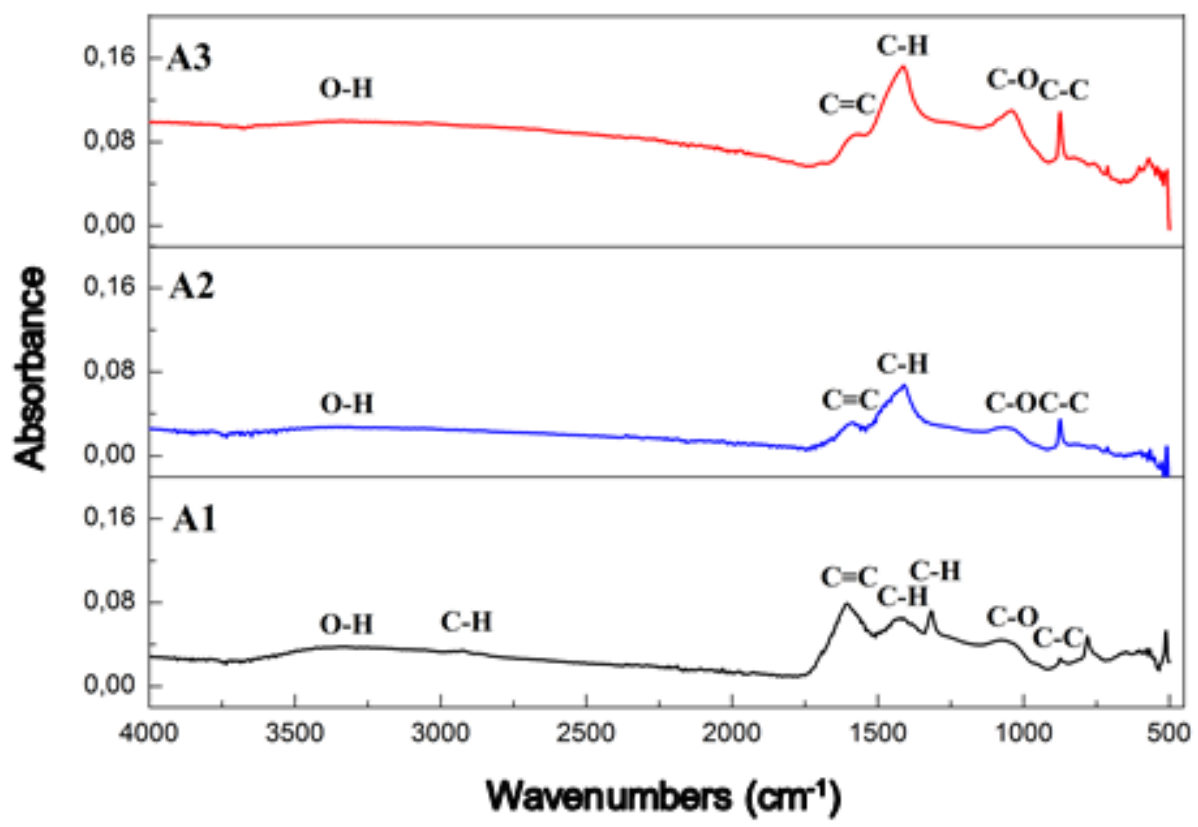

Figure 2. FTIR spectra of carbon derived from water hyacinth at carbonization temperature $400^{\circ} \mathrm{C}$ (sample A1), $500^{\circ} \mathrm{C}$ (sample A2), and $600^{\circ} \mathrm{C}$ (sample A3)

Figure 2 shown the surface functional groups of carbon derived from water hyacinth at a various carbonization temperature. The spectral pattern of the FTIR results in sample A1 shows that there is a vibration of hydroxyl groups $\left(\mathrm{O}-\mathrm{H}\right.$ stretching) at the wavenumber $3324 \mathrm{~cm}^{-1}$. The asymmetric C-H stretching at the wavenumber $2925 \mathrm{~cm}^{-1}$. The band at around $1605 \mathrm{~cm}^{-1}$ indicates a $\mathrm{C}=\mathrm{C}$ stretching vibration of aromatic compounds. The asymmetric $\mathrm{C}-\mathrm{H}$ bending vibration mode of hydrocarbon aliphatic bond at the wavelength of $1414 \mathrm{~cm}^{-1}$. Whereas, a symmetric $\mathrm{C}-\mathrm{H}$ bending group at the wavenumber of $1316 \mathrm{~cm}^{-1}$. C-O stretching vibration observed at around $1076 \mathrm{~cm}^{-1}$. A weak band at the wavenumber $873 \mathrm{~cm}^{-1}$ was describe to C-C stretching vibration. From this results shown that carbon derived from water hyacinth at carbonization temperature of $400^{\circ} \mathrm{C}$ has a little amount of carbon elements.

In a sample A2 with carbonization temperature of $500^{\circ} \mathrm{C}$, the band at around $3324 \mathrm{~cm}^{-1}$ could be ascribed to hydroxyl groups (O-H stretching). Band observed appearing at around $1585 \mathrm{~cm}^{-1}$ for aromatic compounds $(\mathrm{C}=\mathrm{C}$ stretching). The vibration of the asymmetric $\mathrm{C}-\mathrm{H}$ bending at the wavenumber $1409 \mathrm{~cm}^{-1}$. C-O stretching vibration observed at around $1069 \mathrm{~cm}^{-1}$. The band at wavenumber $875 \mathrm{~cm}^{-1}$ for C-C stretching vibration. The peak of the absorption band in FTIR spectra sample A2 was lower than sample A1. This occurs because at a temperature of $500^{\circ} \mathrm{C}$ the absorbance decreases of aromatic compounds and increases in the carbon element which is formed based on the increase in the absorbance value of the $\mathrm{C}-\mathrm{C}$ stretching vibration group.

The functional group in sample A3 looks alike in sample A2. Vibration group of O-H stretching, $\mathrm{C}=\mathrm{C}$ stretching, asymmetric $\mathrm{C}-\mathrm{H}$ bending, $\mathrm{C}-\mathrm{O}$ stretching, and $\mathrm{C}-\mathrm{C}$ stretching were observed at a wavenumber $3338 \mathrm{~cm}^{-1}, 1571 \mathrm{~cm}^{-1}, 1413 \mathrm{~cm}^{-1}, 1039 \mathrm{~cm}^{-1}$, and $875 \mathrm{~cm}^{-1}$, respectively. Spectroscopy analyzed of carbon derived from water hyacinth at a various carbonization temperature shown that the carbonization process with higher temperatures will result in 
changed in functional groups, shifted in wavenumbers, reduced absorption rates and formed a new compounds.

\section{Conclusions}

SEM patterns reveal the porous structure of carbon derived from water hyacinth occurs at carbonization temperature 600. While, temperature 400 and 500 not reveal the porous materials. The carbonization process of water hyacinth at various temperature $(400,500$, and 600 ) indicates that an increase in carbonization temperature causes an increase in the percentage of carbon elements. The resulting sequences were $82.70 \%, 87.43 \%$, and $89.37 \%$. The FTIR peaks shown $\mathrm{OH}, \mathrm{C}-\mathrm{H}, \mathrm{C}-\mathrm{O}$, and $\mathrm{C}=\mathrm{C}$ bonds. The atomic groups and structure present are aromatic, aliphatic, tertiary and secondary hydroxyl structures. The presence of aliphatic and aromatic hydrocarbons in carbon means that it contains fats and oils that are related to butane or isobutene, making it easier to burn or heat up. Likewise, the presence of hydroxyl groups means that there is an alcohol present which could contribute to higher flammability of substances. Hence, water hyacinth is considered a suitable raw material as a renewable energy sources.

\section{References}

[1] International Energy Agency, World Energy Outlook 2018, executive Summary, www.iea.org/weo/, accessed on 16 August 2019.

[2] A Kadiyala, R Kommalapati and Z Huque, 2016, Sustainability, volume 8, page 11811192.

[3] N P Carnaje, R B Talagon, J P Peralta, K Shah and J Paz-Ferreiro, 2018, PLOS ONE, volume 13(11), page 1-14.

[4] X Shen, R R Kommalapati and Z Huque, 2015, Sustainability, volume 7, page 1297412987.

[5] H A Fileto-Perez, J G Rutiaga-Quinones, C N Aguilar-Gonzales, J B Paez, J Lopez and O M Rutiaga-Quinones, 2013, BioResources, volume 8(4), page 5340-5348.

[6] L M Deem and S E Crow, 2017, Reference Module in Earth Systems and Environmental Sciences, page 1-5.

[7] O D Nartey and B Zhao, 2014, Advances in Materials Science and Engineering, page 112.

[8] H Nurdiansah and D Susanti, 2013, Jurnal Teknik POMITS, volume 2(1), page 23019271.

[9] Desi, A Suharman and R Vinsiah, 2015, Prosiding SEMIRATA, page 294-303. 